\title{
EVALUASI KETERCAPAIAN STANDAR PENJAMINAN MUTU KINERJA PENELITIAN, PENGABDIAN DAN HAK PATEN PROGRAM STUDI PGMI UMMAGELANG
}

\author{
Oleh \\ Ahwy Oktradiksa*, Norma Dewi Shalikah, Irham Nugroho, Kanthi Pamungkas Sari, \\ Minzani Aufa, Muis Sad Iman \\ PGMI Universitas Muhammadiyah Magelang \\ *ahwy@ummgl.ac.id
}

diterima 18 Juli 2019, direvisi 21 Agustus 2019, diterbitkan 31 Agustus 2019

\begin{abstract}
Muhammadiyah University of Magelang (UMMagelang) with Study Program Madrasah Ibtidaiyah Teacher Education (PGMI) has a vision "To become a superior and nationally Islamic study program in 2024 the development of Islamic science in the field of teacher professional education $(M I / S D) "$. In order to realize the performance and improvement of PGMI Study Program lecturers based on 17 quality objectives set out in the appendix of the study program vision, in this article only the criteria for research and service are delivered, the PGMI UMMagelang study program refers to the UMMagelang research roadmap. In the last 3 years, lecturers of PGMI were involved in 28 Research and Service Titles. LP3M UMMagelang Internal Funding: 8 Title University Vision Revitalization Program (PRVI) and 9 University Partnership Program (PKU) titles. External Funding for DRPM Kemenristekdikti: 2 titles of Higher Education Leading Basic Research (PDUPT), 1 title of Grant DIPA Kopertais Wilayah X Central Java, 1 title Grant of Magelang regency, 1 title Community Partnership Program (PKM), 1 title Village Partner Development Program (PPDM)
\end{abstract}

\section{Keywords: Research performance, Dedication performance, Publication performance, Intellectual property rights performance}

\section{PENDAHULUAN}

Permendikbud Nomor 49 tahun 2014 yang direvisi dengan Permenristekdikti Nomor 44 tahun 2015, Standar Nasional Pendidikan Tinggi (SN-Dikti) secara jelas mengintegrasikan standar pendidikan, standar penelitian, dan standar pengabdian kepada masyarakat dengan penjelasan yang sangat detail yang masingmasing standar terdiri dari 8 standar turunan (Kemenristekdikti, 2015.(Subba Rao, 2009)

Pamungkas Sari, Minzani Aufa, Muis Sad Iman 


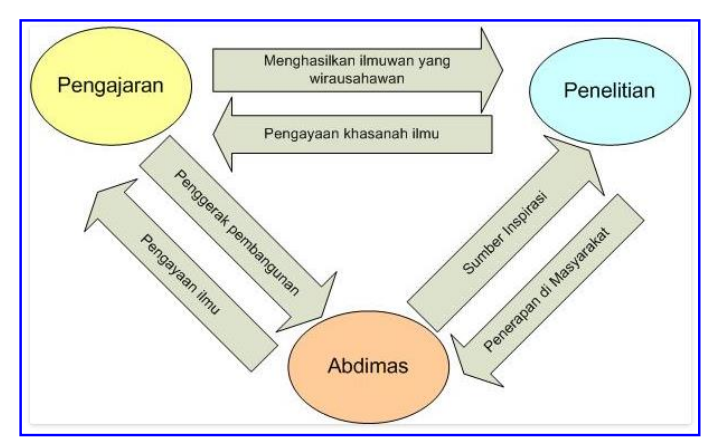

Gambar 1. Tugas Dosen dalam Tridharma Perguruan Sumber : http://link.ummgl.ac.id/2L212

Dosen di Perguruan Tinggi dosen harus bertindak sebagai : a) Pengajar, dosen harus menguasai materi dan mengajarkannya dengan metode yang baik bagi mahasiswa, b) Peneliti, dosen harus meneliti untuk mengembangkan keilmuannya bukan hanya untuk diri sendiri, tetapi juga merupakan bentuk tanggung jawab terhadap pengembangan ilmu pengetahuan yang dimilikinya. c) Abdimas, sebagai tanggung jawab moral dan sosial terhadap masyarakat, dosen harus mau memberikan ilmu yang ia miliki untuk kepentingan orang banyak.

Di Universitas Muhammadiyah Magelang, dan seluruh Perguruan Tinggi Muhammadiyah/ 'Aisyiyah (PTM/A) di Indonesia, selain harus melampaui kriteria standar minimal yang dipersyaratkan Pemerintah, juga wajib untuk melaksanakan standar yang ditetapkan oleh Majelis Diktilitbang PP Muhammadiyah yang tertuang dalam Pedoman Sistem Penjaminan Mutu Internal Perguruan Tinggi Muhammadiyah/ 'Aisyiyah (SPMI-PTM/A). (Setiyo et al., 2018).

Universitas Muhammadiyah Magelang sudah menetapkan Buku Pedoman Penelitian dan Pengabdian Berdasarkan Pengesahan Rektor berdasarkan PM-UMM-09-01/L3 tertanggal 15 Oktober 2018.

Program Studi Pendidikan Guru Madrasah Ibtidaiyah Fakultas Agama Islam Universitas Muhammadiyah Magelang (Prodi PGMI FAI UMMagelang) sebagai bagian dari PTM/A, telah mengimplemantasikan system penjaminan mutu penelitian dibawah koordinasi Badan Penjaminan Mutu (BPM) dan Lembaga
Penelitian, Pengembangan dan Pengabdian kepada Masyarakat (LP3M) yang tidak hanya memenuhi standar nasional, namun sesuai dengan Pedoman SPMI PTM/A.

Untuk itu, sebagai program studi yang memiliki visi unggul dalam "Teknologi Pembelajaran”, Prodi PGMI menyusun roadmap penelitian dan pengabdian yangmengacu pada Agenda Riset Nasional dan Rencana Induk Penelitian Universitas Muhammadiyah Magelang. Kemudian, dalam Sistem Informasi Kinerja Penelitian dan Pengabdian kepada Masyarakat (SIKPPM) pada http://dosen.ummgl.ac.id/. Adapun roadmap penelitian program studi digambarkan sebagai berikut :

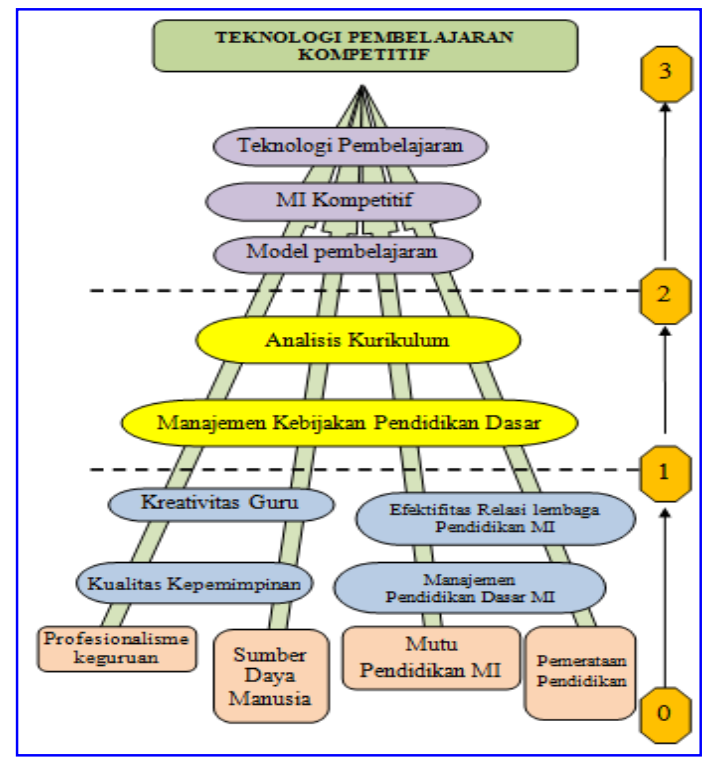

Gambar 1. Roadmap penelitian prodi PGMI

Selama 2015-2018 telah tercatat kegiatan penelitian yang dihasilkan dosendosen program studi Pendidikan Guru MI sebanyak 28 judul, dengan 4 judul mendapatkan pembiayaan dari DRPM melalui skema PTUPT, PPDM, 1 judul dibiayai oleh DIPA Kopertais $\mathrm{X}$ Jawa Tengah, 23 judul sisanya mendapatkanpembiayaan dari internal kampus melalui skema Program Revitalisasi Visi Institusi (PRVI) dan Program Kemitraan Universitas (PKU).

Dari penjelesan diatas, perlu dilakukan pengukuran ketercapaian penelitian dan luarannyamenggunakan instrumen audit 
mutu eksternal (instrumen akreditasi) untuk mengetahui posisi ketercapaian standar penelitian program studi terhadap SN-Dikti. Pada tanggal 11-13 Juli 2019 telah dilakukan Asesmen Lapangan (AL) oleh BAN-PT.

\section{PEMBAHASAN}

\section{a. Deskripsi hasil penelitian dan} pengabdian prodi PGMI

Prodi PGMI membuat sasaran mutu penelitian dan pengabdian yang menjadi pedoman dan target yang harus dilakuakn oleh setiap dosen Prodi PGMI sesuai dengan sasaran mutu prodi tahun 2016-2020 :

Tabel.1.Sasaran Mutu Prodi PGMI

\begin{tabular}{|c|c|c|c|c|c|c|}
\hline No & SASARAN & \multirow{2}{*}{$\begin{array}{c}\text { CAPAIAN } \\
2017 / 2018\end{array}$} & \multicolumn{4}{|c|}{ INDIKATOR PENCAPAIAN } \\
\cline { 4 - 7 } & & $\mathbf{2 0 1 5}$ & $\mathbf{2 0 1 6}$ & $\mathbf{2 0 1 7}$ & $\mathbf{2 0 1 8}$ \\
\hline 1 & $\begin{array}{l}\text { Indeks partisipasi } \\
\text { dosen } \\
\text { penelitian per tahum } \\
\geq 1\end{array}$ & 1 & $\geq 1$ & $\geq 1$ & $\geq 1$ & $\geq 1$ \\
\hline & $\begin{array}{l}\text { Indeks partisipasi } \\
\text { dosen dalam PKM } \\
\text { per tahun } \geq 1\end{array}$ & 1,14 & $\geq 1$ & $\geq 1$ & $\geq 1$ & $\geq 1$ \\
\hline
\end{tabular}

Sumber : menu sasaran mutu Prodi PGMI http://link.ummgl.ac.id/v6w87 /

Dari table diatas dapat dijelaskan jumlah judul penelitian yang sesuai dengan bidang keilmuan Prodi PGMI, yang dilakukan oleh dosen tetap yang bidang keahliannya sesuai dengan Prodi selama tiga tahun terakhir :

Tabel.2.Daftar jumlah laporan penelitian dosen proram studi PGMI

\begin{tabular}{||l|c|c|c|}
\hline \multicolumn{1}{|c|}{ Sumber Pembiayaan } & $\begin{array}{c}\text { TS-2 } \\
\text { 2015/2016 }\end{array}$ & $\begin{array}{c}\text { TS-1 } \\
\text { 2016/2017 }\end{array}$ & $\begin{array}{c}\text { TS } \\
\text { 2017/2018 }\end{array}$ \\
\hline Pembiayaan sendiri oleh peneliti & $(2)$ & $(3)$ & $(4)$ \\
\hline PT yang bersangkutan & 3 & 1 & 5 \\
\hline DRPM Ristekdikti & & & 2 \\
\hline Kemenag RI & & 1 & \\
\hline $\begin{array}{l}\text { Institusi dalam negeri di luar } \\
\text { Depdiknas (Bapeda Kabupaten } \\
\text { Magelang) }\end{array}$ & 1 & & \\
\hline Institusi luar negeri & & & \\
\hline Total & $\mathbf{4}$ & $\mathbf{2}$ & $\mathbf{7}$ \\
\hline
\end{tabular}

Tabel.3.Daftar jumlah laporan pengabdian kepada masyarakat Prodi PGMI

\begin{tabular}{|l|c|c|c|}
\hline $\begin{array}{c}\text { Sumber Dana Kegiatan } \\
\text { Pelayanan/Pengabdian kepada } \\
\text { Masyarakat }\end{array}$ & $\begin{array}{c}\text { TS-2 } \\
\text { 2015/2016 }\end{array}$ & $\begin{array}{c}\text { TS-1 } \\
\text { 2016/2017 }\end{array}$ & $\begin{array}{c}\text { TS } \\
\text { 2017/2018 }\end{array}$ \\
\hline \multicolumn{1}{|c|}{$(2)$} & $(3)$ & $(4)$ \\
\hline Biaya Sendiri & & & \\
\hline PT yang bersangkutan & 3 & 2 & 6 \\
\hline DRPM Ristekdikti & & 1 & 2 \\
\hline Institusi dalam negeri di luar Depdiknas & 1 & & \\
\hline Institusi luar negeri & & 3 & $\mathbf{8}$ \\
\hline Total & $\mathbf{4}$ & \multicolumn{2}{|l}{} \\
\hline
\end{tabular}

Dari tabel diatas dapat dijelaskan bahwa setiap kinerja penelitian dan pengabdian Prodi PGMI selalu mengalami peningkatan yang signifikan berdasarkan skema sebagai berikut :

\section{1) Bedasarkan skema pendanaan dan kompetitiveness}

Sebaran mutu penelitian dan pengabdian masyarakat program studi PGMI disajikan dalam Grafik sebagai berikut.
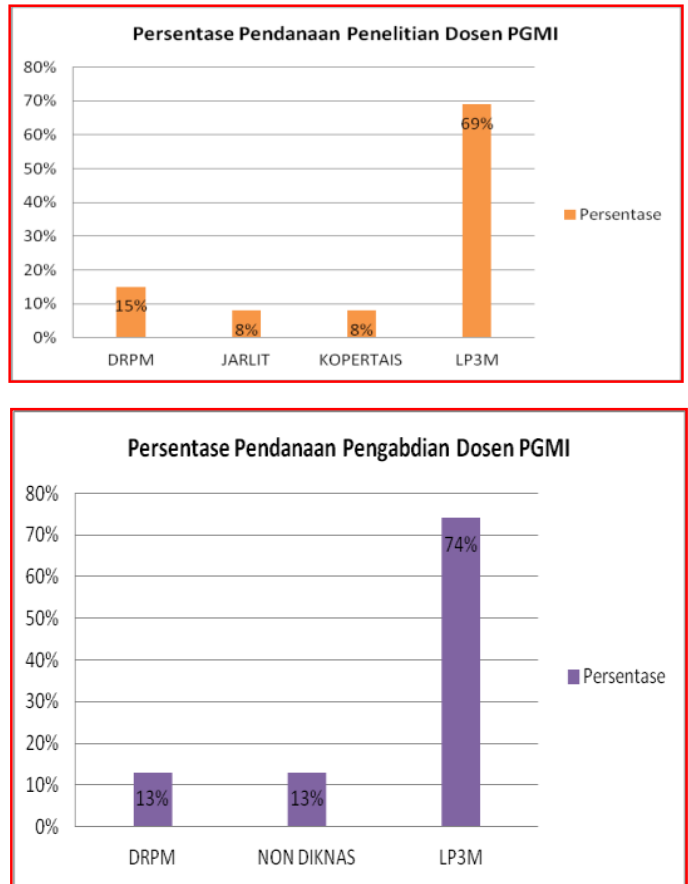

Grafik.2. Mutu pengabdian kepada masyarakat $(\mathrm{PkM})$ dosen Prodi PGMI

Dalam 4 tahun terakhir, dosen program studi PGMI melaksanakan 13 program penelitian; 2 penelitian (15\%) didanai DRPM Ristekdikti, 1 penelitian (8\%) didanai DIPA Kopertais Wil X Jateng, 1 penelitian (8\%) didanai Pusat Penelitian Kabupaten Magelang dan 9 penelitian $(69 \%)$ didanai LP3M melalui pembiayaan APBU, sementara itu 15 program pengabdian kepada masyarakat 2 pengabdian $(13 \%)$ didanai oleh Kemenristekdikti, 2 pengabdian $(13 \%)$ didanai diluar departemen pendidikan, 11 pengabdian $(74 \%)$ didanai oleh LP3M.(Pengantar, n.d.)

\section{2) Bedasarkan standar isi}

Berdasarkan standar isi penelitian (http://link.ummgl.ac.id/Zq1tE) dan standar isi pengabdian (http://link.ummgl.ac.id/9hVbg), adapun capaian penelitian dan dan pengabdian disajikan pada matrik berikut : 


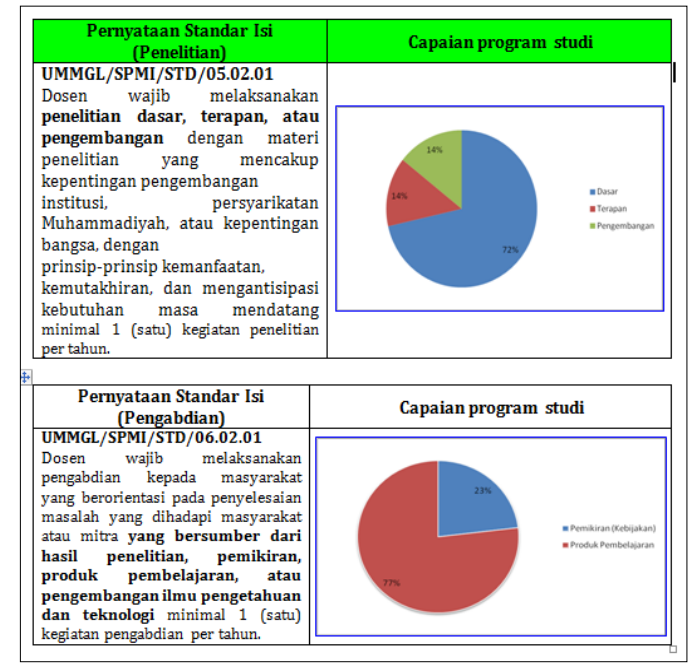

Gambar.2. Standar isi hasil penelitian dan pengabdian dosen Prodi PGMI

\section{3) Berdasarkan hasil diseminasi luaran}

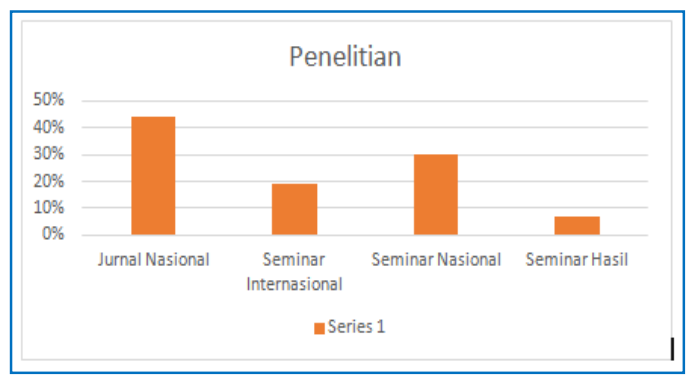

Grafik.3. Diseminasi hasil luaran penelitian dosen Prodi PGMI

Desiminasi hasil penelitian selama 3 tahun terakhir diantaranya melalui :

a) Jurnal nasional (12 artikel),

b) Seminar internasional (5 artikel) ; Ahwy Oktradiksa dan Kanthi Pamungkas Sari, Implementation of Multidirectional Circle Model Madrasah Ibtidaiyah In Realizing The Model Adiwiyata In Magelang, Proceding Internasional.(Oktradiksa \& Sari, n.d.); Kanthi Pamungkas Sari, Ahwy Oktradiksa, Religiosity Correlations With Organizational Citizenship Behavior (Case Study on Madrasah Ibtidaiyah Educators Muhammadiyah in Magelang). Proceding Internasional.(Sari \& Oktradiksa, n.d.)

c) Seminar nasional (8 artikel),

d) Seminar hasil penelitian desentralisasi dan kompetitif nasional ( 2 poster).

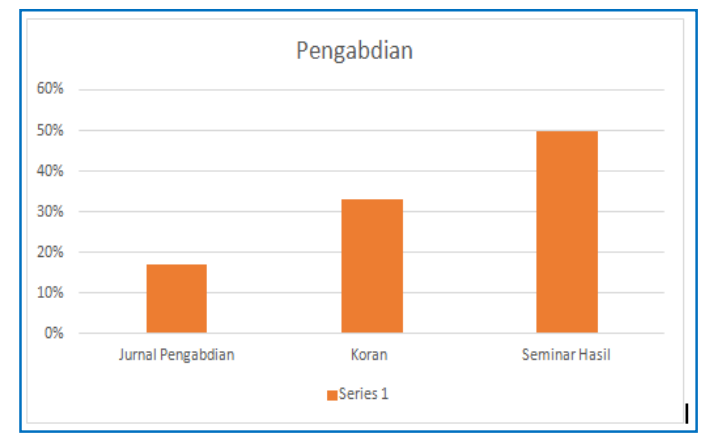

Grafik.4.Diseminasi hasil luaran pengabdian dosen Prodi PGMI

Desiminasi hasil pengabdian masyarakat selama 3 tahun terakhir dilakukan melalui:

a) Jurnal pengabdian masyarakat (ada 2 artikel), sample hasil seminar : Ahwy Oktradiksa, Kanthi Pamungkas Sari, Irham Nugroho, SNP, APE, Learning Strategy In Madrasah Ibtidaiyah of Muhammadiyah, Magelang Regency, Proceding Internasional. (Noh, Mohd Aderi Che, Suhid , Asmawati, Abdul Rahim, 2018).

b) Koran Magelang Express dan Suara Merdeka (ada 4 publikasi),

c) Seminar hasil pengabdian masyarakat (4 artikel) dan (2 Poster)

Sampel artikel : Ahwy Oktradiksa, Kanthi Pamungkas Sari, Irham Nugroho PKM Bagi Madrasah Ibtidaiyah Muhammadiyah Di Kecamatan Salam Kabupaten Magelang, Artikel Jurnal Nasional.(Oktradiksa, Sari, \& Nugroho, 2018) 


\section{4) Berdasarkan hasil luaran Hak Kekayaan Intelektual}

Tabel.4. Daftar Karya Dosen Prodi PGMI yang Memperoleh HaKI

\begin{tabular}{|c|c|c|}
\hline \multirow[b]{2}{*}{ No. } & \multicolumn{2}{|r|}{ Nama Karya ${ }^{i}$} \\
\hline & Paten/HaKI & $\begin{array}{c}\text { Karya yang Mendapat } \\
\text { Pengakuan/Penghargaan dari Lembaga } \\
\text { Nasional/Internasional }\end{array}$ \\
\hline$(1)$ & (2) & (3) \\
\hline$\frac{3}{1}$ & $\begin{array}{l}\text { Hak Cipta Karya an. Alhwy } \\
\text { Oktradiksa (tahun 2017) }\end{array}$ & $\begin{array}{l}\text { Buku Islamic Learning In English } \\
\text { Academic, Purpose) Nomor pencatatan } \\
\text { C00201702281 } \\
\text { http://linkummelacid/f45 EX }\end{array}$ \\
\hline 2 & $\begin{array}{l}\text { Hak Cipta Karya an. Alwwy } \\
\text { Oktradiksa (tahun 2018) }\end{array}$ & $\begin{array}{l}\text { Buku Reading Skill for Educators and } \\
\text { Islamic, Economic Nomor Pencatatan } \\
000107083 \\
\text { http://link }\end{array}$ \\
\hline 3 & $\begin{array}{l}\text { Hak Cipta Karya an. } \\
\text { Irham Nugroho (tahum } \\
\text { 2018) }\end{array}$ & $\begin{array}{l}\text { Buku Sains 2 untuk PGML, Nomor: } \\
\text { Pencatatan } \\
\text { http://linkummelacid/SiwEQ }\end{array}$ \\
\hline 4 & $\begin{array}{l}\text { HKI an. Kanthi } \\
\text { Pamungkas Sari dan } \\
\text { Ahwy Oktradiksa (tahun } \\
\text { 2018) }\end{array}$ & $\begin{array}{l}\text { Bukk Panduan Desa Penyangga Tangguh } \\
\text { (Implementasi metode sister village) } \\
\text { Nomor Pencatatanl : } 000114353 \\
\text { http://linkummglacid/iomuh }\end{array}$ \\
\hline 5 & $\begin{array}{l}\text { HKI an. Kanthi } \\
\text { Pamungkas Sari (tahum } \\
\text { 2018) }\end{array}$ & $\begin{array}{l}\text { Monograf Analisa Situasi Tuberkulosis } \\
\text { (TB), Nomor Pencatatan : 000114366 } \\
\text { http://linkummglacid/Mapga }\end{array}$ \\
\hline 6 & $\begin{array}{l}\text { HKI an. Muis Sad Iman } \\
\text { (tahun 2018) }\end{array}$ & $\begin{array}{l}\text { Buku Seri Studi Islam Pranata Sosial Di } \\
\text { Dalam Islam, Nomor Pencatatan } \\
000114350 \mathrm{htth} \text { / / /inkummglacid/02aeT }\end{array}$ \\
\hline 7 & $\begin{array}{l}\text { HKI an. Suliswiyadi } \\
\text { (tahun 2018) }\end{array}$ & $\begin{array}{l}\text { Buku Metodologi Penelitian Pendidikan } \\
\text { (Pendekatan Konsep \& Aplikasi) } \\
\text { Nomor pencatatan : } 03297\end{array}$ \\
\hline 8 & $\begin{array}{l}\text { HKI an. Suliswiyadi } \\
\text { (tahun 2018) }\end{array}$ & $\begin{array}{l}\text { Program Komputer V: Si - PRAMUDITA } \\
\text { (Sistem Periksa Audit Mutu Program Studi } \\
\text { Terintegrasi Akreditasi } \\
\text { Nomor pencatatan : } 06236\end{array}$ \\
\hline 9 & $\begin{array}{l}\text { HKI an. Suliswiyadi } \\
\text { (tahun 2018) }\end{array}$ & $\begin{array}{l}\text { Kepala Sekolah Entrepremuerial } \\
\text { Leaderhsip (Kepemimpinan Wirausaha) Di } \\
\text { PAUD } \\
\text { Nomor Pencatatan : } 000110217 \\
\text { httD://linkummmglacid/0.0gZ }\end{array}$ \\
\hline 10 & $\begin{array}{l}\text { HKL. An. Annida Nurul } \\
\text { Arafat } \\
\text { (tahun 2018) }\end{array}$ & $\begin{array}{l}\text { Media Pembelajaran PUTRA DAYANG } \\
\text { (Puzzle Tradisional Damdaman Wayang) } \\
\text { Nomor Pencatatan : } 000111262\end{array}$ \\
\hline
\end{tabular}

Sumber : Sentra Haki UMMagelang http://link.ummgl.ac.id/gv56g

\section{b. Pembahasan}

Program penelitian dan pengabdian di prodi PGMI menjadi wajib untuk memenuhi standar mutu dosen, dan kinerja ini menjadi laporan kinerja program studi (LKPS) yang harus dilaporkan ke Universitas Muhamadiyah Magelang tiap tahun akademik sehingga laporan ini menjadi dokumen untuk evidence penyusunan borang akreditasi prodi PGMI pada fase selanjutnya.

\section{SIMPULAN}

Dari hasil analisis ketercapaian sasaran mutu penelitian, pengabdian, publikasi dan hak kekayaan intelektual di Program Studi Pendidikan Guru Madrasah Ibtidiayah Universitas Muhammadiyah Magelang diperoleh data kinerja penelitian, pengabdian, publikasi dan HaKI lebih menggambarkan kondisi riil yang di laporkan dalam bentuk laporan kinerja program studi selaman tiga tahun terakhir, pelaksanaan evaluasi dan pengendalian mutu.

\section{DAFTAR PUSTAKA}

Oktradiksa, A., \& Sari, K. P. (n.d.). Implementation of multidirectional circle model madrasah ibtidaiyah in realizing the model adiwiyata in magelang.

Oktradiksa, A., Sari, K. P., \& Nugroho, I. (2018). PKM Bagi Madrasah Ibtidaiyah Muhammadiyah Di Kecamatan Salam Kabupaten Magelang. Publikasi Pendidikan, $\quad 8(3), \quad 193$. https://doi.org/10.26858/publikan.v8i3.6424

Sari, K. P., \& Oktradiksa, A. (n.d.). Religiosity Correlations With Organizational Citizenship Behavior (Case Study on Madrasah Ibtidaiyah Educators Muhammadiyah in Magelang)

Setiyo, M., Waluyo, B., Saifudin, ., Purnomo, B. C., Munahar, S., Widodo, N., \& Rusdjijati, R. (2018). Evaluasi Ketercapaian Standar Penjaminan Mutu Penelitian Di Program Studi D3 Mesin Otomotif Universitas Muhammadiyah Magelang Dengan Metode Indeks. Jurnal Penjaminan Mutu, 4(1), 48.

Subba Rao, K. (2009). Standards of higher education. Current Science, 97(9), 1276.

Noh, Mohd Aderi Che, Suhid, Asmawati, Abdul Rahim, Z. (2018). International Seminar on Islamic Education (ISIE 2018) Faculty of Islamic Religion, Universitas Muhammadiyah Ponorogo, July 07. International Seminar on Islamic Education (ISIE 2018) Faculty of Islamic Religion, Universitas Muhammadiyah Ponorogo, July 07th, 2018, (Isie 2018), 1-10.

Oktradiksa, A., \& Sari, K. P. (n.d.). Implementation of multidirectional circle model madrasah ibtidaiyah in realizing the model adiwiyata in magelang.

Oktradiksa, A., Sari, K. P., \& Nugroho, I. (2018). PKM Bagi Madrasah Ibtidaiyah Muhammadiyah Di Kecamatan Salam Kabupaten Magelang. Publikasi Pendidikan, $\quad 8(3), \quad 193$. https://doi.org/10.26858/publikan.v8i3.6424

Setiyo, M., Waluyo, B., Saifudin, ., Purnomo, B. C., Munahar, S., Widodo, N., \& Rusdjijati, R. (2018). Evaluasi Ketercapaian Standar Penjaminan Mutu Penelitian Di Program Studi D3 Mesin Otomotif Universitas Muhammadiyah Magelang Dengan Metode Indeks. Jurnal Penjaminan Mutu, 4(1), 48. https://doi.org/10.25078/jpm.v4i1.397

Subba Rao, K. (2009). Standards of higher education. Current Science, 97(9), 1276. 